\title{
Assessment of Attitudes of Cuban University Pharmacy Students Toward Pharmaceutical Care
}

\author{
Alina de las Mercedes Martinez Sanchez ${ }^{1}$ and Abdel Bermúdez del Sol ${ }^{2}$ \\ ${ }^{1}$ Escuela Universitaria de Enfermería y Fisioterapia de Toledo Universidad de Castilla La Mancha,Toledo, España. \\ ${ }^{2}$ Main Pharmacology Professor CEDIMED-VC, Universidad Médica de Villa Clara Santa Clara, Villa Clara,CUBA.
}

\begin{abstract}
Objective: To describe the attitude of Cuban pharmacy students toward pharmaceutical care. Methods: This study is a descriptive approach to the standard Pharmaceutical Care Attitudes Survey among professional fourth year pharmacy students in Cuba. To assess the students' attitudes towards pharmaceutical care, a five-point Likert Scale (rating from 1 = strongly disagree to 5 = strongly agree) was utilized to measure the extent to which the students agreed on 13 statements related to pharmaceutical care. Sociodemographic characteristics including age, country of origin, current professional year, marital status, and pharmacy training experience. The survey tool was distributed to 42 students. High level of confidentiality and anonymity was maintained throughout the study period. Descriptive statistics on the sample characteristics and questionnaire items including means, standard deviations, and frequency distributions were computed. The reliability of the survey was assessed by calculating the Cronbach's alpha. Results: A total of 30 students returned the survey. The main age was 21 years old, 82 percent were female, 70 percent were single (never married), and 5 percent had some pharmacy related work experience. Of the respondents, $90 \%$ agreed or strongly agreed that all pharmacists and pharmacy students should perform pharmaceutical care. About $80 \%$ strongly agreed that providing pharmaceutical care takes too much time and effort. The Cronbach's alpha reached 0.87. Conclusions: Pharmacy students in the study indicated positive attitudes toward pharmaceutical care. Positive attitude ratings were associated with the pharmaceutical care teaching at the university and the teacher role, according to their experiences in this practice.
\end{abstract}

Key words: Attitudes, Cuba, Pharmaceutical care, Pharmacy student`s, Survey.

\section{INTRODUCTION}

The main change currently affecting practice and education in pharmacy in Cuba is the introduction of the pharmaceutical care concept. The government has implemented initiatives to encourage the pharmacist to apply this innovative professional concept: pharmaceutical care was included in the 2005 Cuban Pharmacy Legislation. ${ }^{1}$

With the advent of pharmaceutical care curricula at schools of pharmacy across Cuba have been changed to reflect these developments in pharmacy practice. Since 1990, new study programs have been tested, applied and directed toward a pharmacist capable to satisfy the Cuban society increasing demand for pharmaceutical products and services. An important component of these programs is an introduction to a variety of teaching and learning methods with a particular emphasis on problem-based learning. Experiments, case studies, discussion groups, class assignments, demonstrations and practical experience in pharmacy are included among other teaching methods. In addition, modern automated lecture capture and delivery systems,
Submission Date : 27-03-2016 Revision Date : 07-04-2016 Accepted Date : :06-05-2016

DOI: 10.5530/ijper.50.4.1 Correspondence: Alina de las Mercedes Martinez Sanchez, Av. del General Fanjul 109, 2D, 28044 Madrid, SPAIN. Tel:0034-659234682 E-mail:alimarti2014@gmail. com

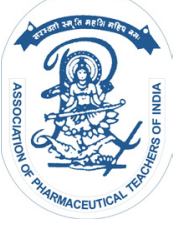

www.ijper.org 
which enable students to access lecture material online, are employed.

The curriculum encourages the development of analytical thinking, problem-solving abilities, and a commitment to lifelong learning. Communication skills, professional ethics, social responsibility, professional citizenship are included in the curriculum as well. It also guarantees knowledge on chemical, biological, social, and clinical sciences that underlie pharmacy and an understanding of the relevance of that knowledge to patients care. Moreover, it provides the skills to apply this knowledge to a specific patient care conditions.

Pharmaceutical care`s philosophy of practice, involves essential professional values such as: empathy, assertiveness, service spirit, willingness for communication, sensitiveness toward the patient; and the clinical pharmacy method applied in the patient-drug relation management were taken into consideration to implement pharmaceutical care in the Cuban pharmacy curricula, incorporating a discipline named Social Pharmacy. The discipline includes three subjects: pharmacy services (includes community and hospital pharmacy, experiences in ambulatory, inpatient and managed care environment), management and special pharmacy services (includes pharmaceutical care practice) and ethics in pharmacy (includes marketing, knowledge on drug distribution, health care delivery system, ethical principles pertaining professional practice). ${ }^{2}$

Cuban pharmacy students are able to speak about pharmaceutical care, and to identify the differences to other practice models; they recover information about patients' most used drugs and common drug-related problems, and obtain information that could support the proposition of a pharmaceutical care plan. Students interrelate with patients by giving educative addresses, handing out brochures and manuals, and evaluate the impact of the education given on the patients' knowledge about diseases and treatments during the clerkship. There is a need to confirm whether the education and training that Universidad de Oriente College of Pharmacy students are receiving are good enough to adoptive positive attitudes toward pharmaceutical care. ${ }^{3}$

In addition, in Cuba, pharmaceutical care practice has not yet been developed by pharmacists in their daily practice. Pharmaceutical care is rarely provided, and it is even less frequent in hospitals. Limitations in inter professional communication and pharmacists' integration into the health care teams have been suggested as possible causes of these deficits. ${ }^{4}$

For countries where pharmaceutical care practice is still evolving fostering positive pharmaceutical care attitude amongst pharmacist should be the first and fundamental strategy to stimulate its wide spread acceptance and implementation. It is equally important to raise positive pharmaceutical care attitudes not only to now-a-days practitioners but more importantly, the practitioners of tomorrow. ${ }^{5}$

A bibliography research revealed many studies describing teaching pharmacy students' knowledge and skills necessary to perform pharmaceutical care. ${ }^{6-10}$ However, the literature is scarce in describing studies that foster the development of positive pharmaceutical care attitudes among pharmacy students and practicing pharmacists. ${ }^{11}$ Most of the reports concerning future pharmacy practitioners' perceptions, understanding, and attitudes towards pharmaceutical care are based on experience in developed countries. As the philosophy of pharmaceutical care spreads to other parts of the world, there is a need to build on professional literature by incorporating evidence from the developing countries. ${ }^{12}$

In 2004, the researcher of this study participated in the initial investigation to ascertain the level of academic qualifications and the arrangement of the pharmacists toward pharmaceutical care practice. ${ }^{13}$ Nevertheless, there is no research reference on evaluating the pharmacy students' attitudes toward pharmaceutical care. In fact, nothing is known about the attitudes of pharmacy students to pharmaceutical care in Cuba. Managing this important information will assist in monitoring the progress in training future pharmacy practitioners in this country. The purpose of this study was to describe the attitude of Cuban pharmacy students toward pharmaceutical care.

\section{MATERIALS AND METHODS}

\section{Study design, participants and settings}

A descriptive study was conducted to the fourth year pharmacy students registered at the "Universidad de Oriente" School of Pharmacy in Santiago de Cuba, Cuba. A total of 42 students were enrolled in the fourth year of the surveyed university and all the participants were involved in this study. According to the curriculum, the concept of pharmaceutical care was introduced in the third year through the Social Pharmacy discipline, specifically through the Delivery System, Legislation and Pharmaceutical Deontology course; in this course, pharmacy students are introduced to ethical dimensions of pharmacy practice, including pharmaceutical care.

\section{Study instrument}

The standard Pharmaceutical Care Attitudes Survey (PCAS) was used in the study. This survey tool is a validated instrument that measures students' attitudes toward pharmaceutical care. It was developed in the 
United States and has already been used and tested in previous studies in different countries such as Africa, Europe, Asia and the United States. ${ }^{14-17}$

The survey was distributed to five randomly selected pharmacy students at the "Universidad de Oriente" College of Pharmacy for clarity, significance, acceptability, and time to accomplish. These five students were excluded from the final study sample. Modifications were made as required in terms of language understanding and question organization before distributing the final survey to the study population.

To assess the students' attitudes towards pharmaceutical care, a five-point Likert Scale (rating from 1= strongly disagree to $5=$ strongly agree) was utilized to measure the extent to which the students agreed with 13 statements related to pharmaceutical care; socio-demographic characteristics including age, country of origin, current professional year, marital status, and pharmacy training experience.

\section{Data collection}

After preparation, validation and reliability of the pilot study, the researcher was granted permission by the Head of School of Pharmacy to conduct the study. The questionnaire was distributed to the fourth year students at the end of the first semester. At this point, it is worth mentioning that the students have shown cooperation and estimable response which has contributed considerably to the realization of the study. The students were also apprised that the completion of the questionnaire would be taken as their agreement to participate in this study. Permission of the respective course coordinator was also granted prior to data collection. High level of confidentiality and anonymity was maintained throughout the study period. A brief explanation was provided regarding the importance of the survey to improve the future pharmaceutical practice and teaching. In addition, the objectives of this research to facilitate the students in completing the questionnaire.

\section{Statistical analysis}

Survey data were downloaded to an Excel $^{\mathbb{P}}$ (Microsoft Corporation, Redmond, WA, USA) spreadsheet, and imported into SPSS (IBM Corporation, Armonk, NY, USA) software, version 7.0, for descriptive and inferential analysis. Descriptive statistics on the sample characteristics and questionnaire items included means; standard deviation and frequency distribution. Cronbach's alpha was calculated to estimate the internal consistency of the responses to questionnaire items.

The mean, standard deviation, and range for the three separate constructs were determined (Table 1). The frequency for each of the PCAS items was determined (Table 2).

\section{RESULTS}

\section{Cuba Pharmacy Education framework}

Cuba is a Caribbean archipelago of about 11238317 million inhabitants. ${ }^{13}$ Cuba is internationally recognized for its attainments in the fields of education and health, with social services that surpass those of most developing nations and in certain sectors, are comparable to those of the developed countries. At present, there are 3392 pharmacists, and 2117 pharmacies in a diverse geographic distribution with a national average of 18.34 pharmacies per 100,000 inhabitants.

In Cuba, pharmacy studies began in 1734 but it was not until 1833 that the studies became regulated. There are three universities offering Bachelor of Science in Pharmacy (BScPharm) degree, located in the north, center and south of the country, respectively. A research by Sánchez ${ }^{18}$ described four pharmacy curricula applied in Cuba, namely: A-C1. In general, the programs A and B provided a foundation in the enabling sciences, physics, chemistry and technology, with a strong focus on chemical education. Program C represented the introduction of clinical aspects into pharmacy education in Cubaa qualitative leap in Cuban higher education. Unlike the previous curriculum, these programs strengthen pharmacy training in skills and knowledge and orient it toward clinical practice. To support clinical training, subjects like human anatomy and clinical biochemistry were introduced. In general, this curriculum was more modularized and integrated. O Program C1 introduces a variety of teaching and learning methods with particular emphasis on problem-based learning. Experiments, case studies, discussion groups, class assignments, demonstrations, and practical experience in pharmacy are included among teaching methods. This curriculum promotes the development of analytical thinking, problem-solving abilities, and a commitment to lifelong learning. Communication skills, professional ethics, social responsibility, professional citizenship are also included in the curriculum. Currently, a new pharmacy program is developed in Cuba. The Program D aims to strengthening basic training, raising humanism training, greater flexibility in the duration of studies, more rational use of human and material resources, achieve higher virtualization, and more qualitative and inclusive assessment system. ${ }^{19}$ The Cuban Pharmacy curriculum includes basic science courses and specialized coursework in pharmacy. Table 3 lists courses taught in the revised curriculum. 
Table 1: Means and standard deviations of survey items $(n=30)$

\begin{tabular}{|c|c|c|}
\hline Items & $\begin{array}{l}\text { Likert scorea } \\
\text { (Mean) }\end{array}$ & SDb \\
\hline All pharmacists should perform pharmaceutical care. (PD) & 3,13 & 0,97 \\
\hline $\begin{array}{l}\text { Pharmacists in all health care settings primary responsibility should be to prevent and solve medication- } \\
\text { related problems. (PD) }\end{array}$ & 3,06 & 0,86 \\
\hline Pharmacists' primary responsibility should be to practice pharmaceutical care. (PD) & 2,70 & 0,95 \\
\hline Providing pharmaceutical care takes too much time and effort. (ROE) & 2,90 & 0,95 \\
\hline $\begin{array}{l}\text { Providing pharmaceutical care is not worth the additional workload that it places on the pharmacist. } \\
\text { (ROE) }\end{array}$ & 2,93 & 0,98 \\
\hline Pharmacy students can perform pharmaceutical care during their clerkships. (PB) & 3,03 & 0,99 \\
\hline I think the practice of pharmaceutical care is valuable. (PB) & 2,86 & 1,07 \\
\hline $\begin{array}{l}\text { I would like to perform pharmaceutical care as a pharmacist } \\
\text { practitioner. (PB) }\end{array}$ & 2,80 & 0,99 \\
\hline Providing pharmaceutical care is professionally rewarding. (PB) & 2,90 & 0,84 \\
\hline I feel that pharmaceutical care is the right direction for the profession to be headed. (PB) & 2,83 & 1,01 \\
\hline $\begin{array}{l}\text { I feel that the pharmaceutical care movement will benefit } \\
\text { pharmacists. (PB) }\end{array}$ & 2,63 & 0,66 \\
\hline $\begin{array}{l}\text { I feel that the pharmaceutical care movement will improve } \\
\text { patient health. (PB) }\end{array}$ & 2,53 & 0,68 \\
\hline $\begin{array}{l}\text { I feel that practicing pharmaceutical care would benefit my professional career as a pharmacy } \\
\text { practitioner. (PB) }\end{array}$ & 2,50 & 0,82 \\
\hline
\end{tabular}

aLikert Scale: 1 = strongly agree, 2 = agree, 3 = neutral, 4 = disagree, 5 = strongly disagree.

bStandard Deviation

PB: Professional Benefit

ROE: Return on Effort

PD: Professional Duty.

\begin{tabular}{|c|c|c|c|c|c|}
\hline \multirow[t]{2}{*}{ Items } & \multicolumn{5}{|c|}{ Frequency responses } \\
\hline & 1 & 2 & 3 & 4 & 5 \\
\hline All pharmacists should perform pharmaceutical care. & 13 & 10 & 2 & 4 & 1 \\
\hline $\begin{array}{l}\text { Pharmacists in all health care settings primary responsibility should be to prevent and solve } \\
\text { medication-related problems }\end{array}$ & 15 & 8 & 1 & 5 & 1 \\
\hline Pharmacists' primary responsibility should be to practice pharmaceutical care & 18 & 4 & 4 & 3 & 1 \\
\hline Providing pharmaceutical care takes too much time and effort & 17 & 10 & 1 & 2 & 0 \\
\hline Providing pharmaceutical care is not worth the additional workload that it places on the pharmacist & 13 & 14 & 1 & 2 & 0 \\
\hline Pharmacy students can perform pharmaceutical care during their clerkships & 15 & 9 & 4 & 2 & 0 \\
\hline I think the practice of pharmaceutical care is valuable & 13 & 7 & 1 & 8 & 1 \\
\hline I would like to perform pharmaceutical care as a pharmacist practitioner & 18 & 5 & 1 & 5 & 1 \\
\hline Providing pharmaceutical care is professionally rewarding & 13 & 7 & 4 & 6 & 0 \\
\hline I feel that pharmaceutical care is the right direction for the profession to be headed & 12 & 8 & 2 & 7 & 1 \\
\hline I feel that the pharmaceutical care movement will benefit pharmacists & 14 & 9 & 1 & 3 & 3 \\
\hline I feel that the pharmaceutical care movement will improve patient health. & 10 & 12 & 3 & 5 & 0 \\
\hline $\begin{array}{l}\text { I feel that practicing pharmaceutical care would benefit my professional career as a pharmacy } \\
\text { practitioner }\end{array}$ & 11 & 8 & 3 & 6 & 2 \\
\hline
\end{tabular}


Table 3: Cuban Bachelor of Pharmacy curriculum ${ }^{* *}$

\begin{tabular}{|c|c|}
\hline First professional year & Third professional year \\
\hline $\begin{array}{l}\text { Philosophy and Society } \\
\text { Capitalism and Political Economic } \\
\text { English Language I } \\
\text { English Language II } \\
\text { Physical Education I } \\
\text { Physical Education II } \\
\text { Mathematic I } \\
\text { Mathematic II } \\
\text { Biostatistics } \\
\text { Physic I } \\
\text { General Chemistry } \\
\text { Pharmaceutical Inorganic Chemistry } \\
\text { Elective I* }\end{array}$ & $\begin{array}{l}\text { Bioorganic chemistry III } \\
\text { Cellular and Molecular Biology } \\
\text { Human Anatomy } \\
\text { General Biochemistry } \\
\text { Physiology } \\
\text { Microbiology } \\
\text { Drug Control I } \\
\text { Pharmaceutical Technology I } \\
\text { Pharmaceutical Technology II } \\
\text { Drug Supply System and Pharmacy dispensary }\end{array}$ \\
\hline $\begin{array}{l}\text { Second professional year } \\
\text { Socialism and Political Economic } \\
\text { English Language III } \\
\text { English Language IV } \\
\text { Physical Education III } \\
\text { Physical Education IV } \\
\text { Physic II } \\
\text { Bioorganic Pharmaceutical Chemistry I } \\
\text { Bioorganic Pharmaceutical Chemistry II } \\
\text { Chemistry-Physic I } \\
\text { Chemistry -Physic II } \\
\text { Pharmaceutical Chemical Analysis } \\
\text { Pharmaceutical Instrumental Analysis } \\
\text { Pharmaceutical Services, Legislation and Deontology } \\
\text { Socio-Political theory } \\
\text { Elective II* } \\
\text { Elective III* }\end{array}$ & $\begin{array}{l}\text { Fourth professional year } \\
\text { Social problems of Science and Technology } \\
\text { Pharmaceutical Chemistry I } \\
\text { Clinical Biochemistry } \\
\text { Pharmacology I } \\
\text { Immunology } \\
\text { Chemistry of Natural Products } \\
\text { Pharmacology II } \\
\text { Drug Control II } \\
\text { Quality Assurance of Medicines } \\
\text { Pharmaceutical Technology III } \\
\text { Pharmaceutical Technology IV } \\
\text { Pharmacokinetics } \\
\text { Bio- Pharmacy } \\
\text { Production of Medicines } \\
\text { Fifth professional year } \\
\text { Specialty Pharmaceutical Services and Management } \\
\text { Pharmaceutical Chemistry II } \\
\text { Pharmacotherapy } \\
\text { Toxicology } \\
\text { Hospital Pharmacy } \\
\text { Pedagogical Training } \\
\text { Final Thesis Project }\end{array}$ \\
\hline
\end{tabular}

*Electives: Students may choose electives from courses approved by the School of Pharmacy Curriculum Committee available during each semester. **Source: Ministerio de Educación de Cuba. Universidad de la Habana, Instituto de Farmacia y Alimentos. Plan de Estudios de Farmacia. http://www.ifal. uh.cu/node/11. Accessed 10 April 2016. (Credits are not recorded).

\section{Students' sociodemographic characteristics}

A total of 30 questionnaires were returned by the participants, giving the response rate of $71.4 \%$. The number of females was higher than male students $(82 \%$ vs $18 \%)$. Majority of the participants were single $(70 \%)$. Respondents were aged between 19 and 24 years, with a main age of 21 years \pm standard deviation of 1.33 years. Only $5 \%$ had some prior pharmacy practice experience.

\section{Students' attitude toward pharmaceutical care}

The main individual items are fairly homogeneous with values ranging from 4.03 to 4.53 . The standard deviations are also fairly homogenous with values ranging from 0.60 to 0.94 . On eight of the 13 items, respondents used the full range of possible responses; and for five items, respondents used four of the five possible responses. $86 \%$ of the respondents agreed or strongly agreed that all pharmacists and pharmacy students should perform pharmaceutical care. About $90 \%$ also agreed/strongly agreed that the pharmaceutical care movement will benefit pharmacists. At the same time, about $80 \%$ also agreed/strongly agreed that providing pharmaceutical care takes too much time and effort. The item response "1= strongly disagree" was least likely to be used by the students. Generally, the distribution of item responses for each point are positively skewed, as the most frequently selected response was " $1=$ strongly agree". The Cronbach coefficient alpha was 0.87 . 


\section{DISCUSSION}

Contributing to Cuba's effectiveness in primary care is its provision of pharmacy services, which have become a significant aspect of drug policy. Nevertheless, in contrast to the remarkable standing of the Cuban health system in the public health services, there is a scarcity of published works related to Cuban pharmaceutical services. This makes it problematic to adequately assess the impact of pharmaceutical services on the system. ${ }^{20}$ Within the hospital sector, pharmacists assume a variety of roles and responsibilities appropriate with their capability and education. Pharmacists take extensive clinical responsibilities for monitoring patients' drug therapy, and they also work with physicians and other health professionals as part of multidisciplinary teams. Furthermore, they plan, monitor and evaluate drug programs or regimens and may advise hospitalized patients on the use of medications before the patients are discharged. ${ }^{21}$ Pharmacists in community pharmacies dispense medications and counsel patients on the use of prescription and over-the-counter medications. They likewise advise patients about general health themes, such as diet, exercises, and stress management. ${ }^{22}$ Some research projects have been carried out which have stimulated communitybased family physicians to work collaboratively, and now in many cases they locate their practices together with other health professionals, including pharmacists. ${ }^{23}$ Although efforts are made as yet in generalizing the practice of pharmaceutical care, it is far from standardized and not yet encompassed by the majority of practicing pharmacists now-a-days. Pharmacist's role continues mainly devoted to activities not directly associated to patient care, whereas clinical roles in the practice of pharmaceutical care remain limited. Such is to be expected, as usually health authorities, as well as health care teams, are applying pharmaceutical care experimentally. ${ }^{24}$

Overall, students in this study had high positive attitudes toward pharmaceutical care. Our results are in line with other studies carried out to the same purpose. A research conducted by Sukhyang ${ }^{25}$ reported that of a total of 123 pharmacy students participating in the study; all respondents agreed that pharmaceutical care is the right direction for the provision to be headed and that pharmaceutical care will improve patients health. In addition, this study stated the necessity to improve pharmacy clerkships and to promote pharmaceutical care. Similarly, in our study most respondents considered that, pharmacy students can perform pharmaceutical care during their clerkship. Other study carried out by Tsega et al. ${ }^{26}$ in Ethiopia, indicated a positive attitude toward pharmaceutical care. Almost all respondents agreed that the primary responsibility of pharmacists in the healthcare setting was to prevent and solve medicationrelated problems $(98.5 \%)$, practice of pharmaceutical care was valuable $(89.3 \%)$ and the pharmaceutical care movement will improve patient health (95.4\%), -respectively. Similarly, the results of this study support the impact of clerkship on students' positive attitude toward pharmaceutical care. In Qatar, research results have also revealed pharmacy students' positive attitudes toward pharmaceutical care. ${ }^{27}$ All respondents agreed that the pharmacist's primary responsibility is to prevent and resolve medication therapy problems. Most respondents believed that pharmaceutical care provision is professionally rewarding and that all pharmacists should provide pharmaceutical care $(93 \%$ and $91 \%$ of respondents, respectively). In Al-Arifi ${ }^{16}{ }^{16}$ study, $95.2 \%$ felt that pharmaceutical care movement will improve the patients `health, $94.9 \%$ thought that the practice of pharmaceutical care is valuable, $85 \%$ that all pharmacists should perform pharmaceutical care, whereas, about two third $(64.5 \%)$ thought that students should perform pharmaceutical care during their clerkship, were reported by pharmacy students ( $\mathrm{n}=214)$. According to $\mathrm{El} \mathrm{Hajj^{27 }}$ our results suggest that the inclusion of a separate course on pharmaceutical care in the curriculum did not appear to be essential to nurture the students' positive attitudes.

Our study data suggest that participants, who had more practical experience hade more positive attitudes toward pharmaceutical care. This is not unexpected for Cuba pharmacy students. It is plausible that those students who have completed more clerkship realize the possibility to learn more effectively when they are involved in their learning at the clinical settings. According to Langlois, ${ }^{28}$ teaching at the clinical setting is a chance to provide the students with the opportunity to learn about interdisciplinary teams within the health care system. It has been argued that for pharmacists to apply their knowledge in the context of direct patients care, the most advantageous learning will happen when learners use knowledge to perform significant tasks. The earlier pharmacy students are exposed to real patients, the more likely they are to develop pharmaceutical care skills and positive pharmaceutical care attitudes. ${ }^{29}$

Results suggest that the pharmacy curriculum is successful in positively influencing students' attitudes toward pharmaceutical care as indicated by the scores of the survey questions. This also suggests that Social Pharmacy subjects, recently introduced into the curriculum, positively influenced students' willingness and desire to provide pharmaceutical care to patients. Similar investigation conducted at the University of Georgia College of Pharmacy in order to evaluate the effects of a Clinical 
Applications course on students' pharmaceutical care attitudes has shown students scored significantly higher on post-PCAS than the pre-PCAS for 12 of the 13 items. $^{30}$

In our study, some students have shown a negative disposition towards pharmaceutical care refer to the time and efforts required to provide it. This is somewhat expected since pharmaceutical care is still in its developmental stage in the country and many of the premises were students may had worked might not carry out pharmaceutical care practice. Therefore, pharmacy students are exposed to training in places, which the pharmaceutical care practice is not implemented, thus, they are not likely to adopt an active practice in which complete pharmaceutical care is provided. This brings about the need to have pharmacy experiential training sites that are designed to prepare Cuban pharmacy students for pharmaceutical care practice.

\section{STUDY LIMITATIONS}

Data presented here are a self-report of the students' attitudes toward pharmaceutical care. Furthermore, our results of positive attitudes to pharmaceutical care are from pharmacy students at a Cuban University and may not be shared by students from other pharmacy colleges in the country that follow the same curriculum.

\section{CONCLUSIONS}

Positive attitude ratings were associated with the pharmaceutical care teaching at the university and the teacher`s role, according to their experiences in this practice. Studies are also needed using the PCAS or modified versions of this instrument to measure the influence of educational programs on students' pharmaceutical care attitudes. Longitudinal studies determining the duration of the positive effects of programs on students and practitioners' attitudes toward pharmaceutical care are needed. This study serves as a starting point for the development of future researches and evaluative studies assessing programs that may positively influence students' attitudes concerning pharmaceutical care. As the first of its kind is considered an important contribution, especially because it provides a baseline evidence to monitor changes regarding transitions toward pharmaceutical care education and practice in Cuba.

\section{WHAT THIS STUDY ADDS}

1. This is the first published study carried out in Cuba to assess the attitudes of pharmacy students toward pharmaceutical care, after the introduction of this topic in the curriculum.

2. This study can be useful for guiding pedagogical actions concerning to the implementation of pharmaceutical care in the curriculum, and to improving the patient centered care teaching at both, the classroom and the clinical setting.

\section{ACKNOWLEDGEMENTS}

We want to thank to all the participating students from the University of Oriente School of Pharmacy. To Mr. Manuel Antonio Reyes Sampedro, Graduate and Master in Translation and Interpretation of the English Language for his assistance in the use of the English Language during the preparation of this article.

\section{CONFLICT OF INTEREST}

The author reports no conflicts of interest. The author alone is responsible for the content and writing of the article.

\section{SUMMARY}

- Pharmaceutical care is the main change currently affecting practice and education in pharmacy in Cuba.

- There is a scarcity of published works related to Cuban pharmaceutical services.

- The Cuba pharmacy curriculum is successful in positively influencing students' attitudes toward pharmaceutical care.

\section{About Author}

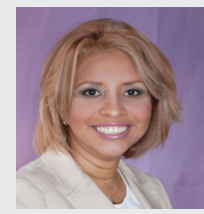

Alina M. Sánchez, PhD: Working as Pharmacology Professor at the Physiotherapy and Nursing School in Toledo, Universidad de Castilla La Mancha, Spain. Alina M. Sánchez has 40 paper publications, also has 4 books published. She received a FIP Award in 1999 to attend the World Pharmacy Education Congress. Currently, she is the Main Coordinator of the Project for the continuing professional development for pharmacists from Africa speaking-Portuguese countries (CPD/APSP). 


\section{REFERENCES}

1. Ministerio de Salud Pública de Cuba. Manual de Normas y Procedimientos en Farmacia Comunitaria. Dirección Nacional de Farmacia y Óptica; 2005. http://www.sld.cu/galerias/pdf/ sitios/revfarmacia/manual_normas_y_procedimientos._farmacia_comunitaria._2005.pdf. Accessed 8 April 2016.

2. Martínez Sánchez A. Pharmacy education in Cuba. Pharm World Sci. 2010; 32: 696-700. http://dx.doi.org/10.1007/s11096-010-9434-5 ; PMid:20842528.

3. Sánchez AMM. Bachelor of Pharmacy Degree in Cuba: New Educational Challenges. Am J Pharm Educ. 2011;75(1):Article 13.

4. Ramalho de Oliveira D, Dupetey-Varela N, Sedeño C. What is the role of the pharmacist? Physicians' and nurses' perspectives in community and hospital settings of Santiago de Cuba. Braz J Pharm Sci. 2011;47(4):709-18. http:// dx.doi.org/10.1590/S1984-82502011000400007

5. Chisholm MA, Hawkins DW, Taylor AT. Providing pharmaceutical care: Are pharmacy students beneficial to patients?, Hosp Pharm. 1997;32(3):370-5.

6. Katoue MG, Awad Al, Schwinghammer TL, Kombian SB. Pharmaceutical care education in Kuwait: pharmacy students' perspectives. Pharm Pract (Granada). 2014;12(3):411. http://dx.doi.org/10.4321/S188636552014000300002

7. Mesquita AR, Souza WM, Boaventura TC, Barros IM, Antoniolli AR, Silva $W B$, et al. The effect of active learning methodologies on the teaching of pharmaceutical care in a Brazilian pharmacy faculty. PLoS One. 2015;10(5):e0123141. http://dx.doi.org/10.1371/journal.pone.0123141; PMid:25969991 PMCid:PMC4430170

8. McDonough RP, Bennet MS. Community pharmacy improving communication skills of pharmacy students through effective precepting. Am J Pharm Educ. 2006;70(3):58. http://dx.doi.org/10.5688/aj700358; PMid:17136179 PMCid:PMC1636963.

9. Menendez, E., Balisa-Rocha, B., Jabbur-Lopes M, Costa W, Nascimento $J R$, Dósea M, Silva L, et al. Using a virtual patient system for the teaching of pharmaceutical care. Int J Med Inform. 2015;84(9):640-6. http://dx.doi. org/10.1016/j.jmedinf.2015.05.015; PMid:26077512.

10. Limberger JB. Active teaching-learning methodologies for pharmaceutical education: a report on experience. Interface: Comunicação, Saúde e Educação. 2013;17(47):969-75

11. Cipolle R, Strand LM, Morley P. Pharmaceutical Care Practice. $1^{\text {st }}$ ed. New York, NY: McGraw Hill, Inc; 1998:379.

12. Ghada A, Massad B. An explorative study on pharmaceutical care practice from the perspective of pharmacists in Malaysia. Accessed at www.eprints. usm.my/9528/1/an_explorative_study_on_pharmaceutical_care_practice_ from_the_perspective_of_pharmacists_in_malaysia.pdf, April 20, 2010.

13. Mateu L, González H, Sedeño C. Observatorio farmacéutico: conocer y transformar. Rev OFIL. 2005;15(4):33-8.

14. Chisholm MA, Wade WE. Factors influencing students' attitudes toward pharmaceutical care. Am J Health Syst Pharm. 1999;56(22):2330-5.
15. Udeogaranya PO, Ukwe CV, Ekwunife OI. Assessment of attitudes of University of Nigeria pharmacy students toward pharmaceutical care. Pharm Pract. 2009;7(3):145-9. http://dx.doi.org/10.4321/s188636552009000300003.

16. Al-Arifi MN. Pharmacy students' attitudes toward pharmaceutical care in Riyadh region Saudi Arabia. Pharm World Sci. 2009; 31(6):677-681. http://dx.doi.org/10.1007/s11096-009-9331-yPMid:19771528.

17. Martin BC, Chisholm MA. Cross-validation of an instrument measuring students' attitudes toward pharmaceutical care. Am J Pharm Educ. 1999;63:46-51.

18. Sánchez AM. Pharmacy education in Cuba. Pharm World Sci. 201;32(6):696700. http://dx.doi.org/10.1007/s11096-010-9434-5 ; PMid:20842528.

19. De Armas R, Espín N. El sistema de educación superior de la República de Cuba. http://tuning.unideusto.org/tuningal/images/stories/presentaciones/ cuba_doc.pdf. Accessed April 18, 2016.

20. Sánchez AM. A New Approach to Health Services and Pharmacy in Cuba. Pharmacotherapy. 2015;35(12):1100-8. http://dx.doi.org/10.1002/phar.1663; PMid:26684551.

21. Martinez AM, De la Torre AM. Impact of clinical pharmacy services on a Cuban pediatric hospital. Pharmacotherapy. 2002;22(10):1385

22. Fernández SA, Rodríguez RD. Exploración de la disponibilidad de los servicios farmacéuticos comunitarios cubanos. Revista de la OFIL. 2005;15(1):21-7.

23. Debesa F, Giménez G, Firgueras A. Spontaneous reporting of adverse drug reactions in Cuba: integrating continuous education, training and research in a network approach. Br J Clin Pharmacol. 2002;54:333-6.

24. Lores D. Portfolio of Services of Municipal Home Community Pharmacy. Infarmate. 2009; 25(5). Retrieved from http://www.slideshare.net/ Infarmate/13-cartera-de-servicios-farmaciacomunitaria.

25. Sukhyang L. Evaluation of Pharmacy Students' Attitudes Toward Pharmaceutical Care and Career Choices Following Interdisciplinary Inpatient Clerkships. Korean J Clin Pharm. 2014;24(2):80-89.

26. Tsega B, Bhagavathula AS, Sarkar BR, Melaku T, Shewamene Z. Impact of clerkship attachments on students' attitude toward pharmaceutical care in Ethiopia. Adv Med Educ Pract. 2015;6:385-91. http://dx.doi.org/10.2147/ AMEP.S80802 ; PMid:26056513 PMCid:PMC4445313.

27. El Hajj MS, Hammad AS, Afifi HM. Pharmacy students' attitudes toward pharmaceutical care in Qatar. Ther Clin Risk Manag. 2014;10:121-9. http:// dx.doi.org/10.2147/TCRM.S56982PMid:24591836 PMCid:PMC3938321

28. Langlois $\mathrm{J}$, Thach $\mathrm{S}$. Teaching and learning styles in the clinical setting. Fam Med. 2001;33(5):344-6.

29. Laurence L, Sherman J, Adams E. Pharmacy Students' Perceptions of Pharmaceutical Care in Retail and Clinic Settings. Am J Pharm Educ. 2004;68 (1): 4.

30. Chisholm MA, Wade WE. Using actual patients in the classroom to develop positive student attitudes toward pharmaceutical care. Am J Pharm Educ. 1999;63:296-9. 